\title{
Decline in Plasma Retinol in Unconjugated Hyperbilirubinemia Treated with Bilirubin Adsorption Using an Anion-Exchange Resin
}

\author{
Hiroshi Ihara, ${ }^{1, *}$ Yoshio Shino, ${ }^{1}$ Naotaka Hashizume, ${ }^{1}$ \\ Tsugutoshi Aoki, ${ }^{2}$ Yasuyuki Suzuki, ${ }^{3}$ Yasuko IGARAsI ${ }^{3}$ \\ and Chikayuki NAITO ${ }^{3}$ \\ Departments of ${ }^{1}$ Laboratory Medicine and ${ }^{2}$ Pediatrics, Toho University, \\ Ohashi Hospital, Meguro-ku, Tokyo 153-0044, Japan \\ ${ }^{3}$ Department of Medicine, Teikyo University, School of Medicine, \\ Itabashi-ku, Tokyo 173-0003, Japan
}

(Received September 6, 1997)

Summary When an anion-exchange resin column (Plasorba BR-350) was used for the treatment of unconjugated hyperbilirubinemia, we found an unexpected decrease in plasma retinol (vitamin A) concentrations in a patient with type I Crigler-Najjar syndrome. The purpose of our study was to investigate the mechanism of this decrease in plasma retinol. When the patient's serum bilirubin exceeded the bilirubin binding capacity of $14.7 \mu \mathrm{mol}$ bilirubin/g serum albumin (i.e., $720 \mu \mathrm{mol} / \mathrm{L}$ of bilirubin), abrupt deterioration of the patient's neurologic status (suppression in his gait and speech) occurred, so the need to apply plasmapheresis to reduce the unconjugated bilirubin was indicated. Blood was drawn from the radial artery at a flow rate of $160 \mathrm{~mL} / \mathrm{min}$ and pumped into a membrane plasma separator at a rate of $40 \mathrm{~mL} / \mathrm{min}$. The plasma was passed through the bilirubin adsorbent column and returned to the venous blood line of the plasma separator. Plasma samples were taken at the inlet and outlet of the bilirubin adsorbent column before and after treatment. The concentration of unconjugated bilirubin in plasma was effectively reduced by the perfusion, but plasma retinol was coincidentally decreased by the perfusion to vitamin A deficiency levels. The patient's plasma retinol was $2,127 \mathrm{nmol} / \mathrm{L}$ at the beginning of therapy and decreased to $1,492 \mathrm{nmol} / \mathrm{L}$ after repeated adsorption treatments. As the amounts of decrease in retinol $(912 \pm 123 \mathrm{nmol} / \mathrm{L})$ after the perfusion were almost equal to those in retinol-binding protein $(1,010 \pm 192 \mathrm{nmol} / \mathrm{L})$, retinol may have been removed as a form of holo retinol-binding protein. Decreases in retinol and retinol-binding protein levels were also observed in low-density lipoprotein (LDL) apheresis with a dextran sulfate column (i.e., a cation-exchange resin column). In the patient with Crigler-Najjar

*To whom correspondence should be addressed. 
syndrome, retinol taken dietarily was removed by plasmapheresis. However, the patient manifested no clinical symptoms associated with vitamin A deficiency, since his liver storage of retinol could supply the loss caused by plasmapheresis treatment. We should measure plasma retinol concentrations to evaluate the loss of retinol during plasmapheresis treatment coupled with an anion-exchange resin column.

Key Words plasma perfusion, bilirubin, retinol, vitamin A, anionexchange resin

Plasma perfusion using an anion-exchange resin has been widely applied, and the effectiveness of the reduction of bilirubin for the treatment of hyperbilirubinemia has been described $(1,2)$. Despite a marked decrease in plasma bilirubin by the column, no significant loss of patient's plasma constituents such as plasma proteins were documented $(2,3)$. However, during therapeutic plasmapheresis to remove unconjugated bilirubin using an anion-exchange resin for a patient with severe unconjugated hyperbilirubinemia, we found a simultaneous decrease in plasma retinol (vitamin A). Although bilirubin was effectively removed from the plasma, the patient's plasma retinol concentration was decreased from ca. 2,127 to $1,492 \mathrm{nmol} / \mathrm{L}$ when plasmapheresis treatment had been performed for four mo. As vitamin A is one of the essential vitamins, we designed the following studies on an anion-exchange column to investigate the mechanism of the removal of retinol during plasmapheresis treatment.

\section{Patient and methods}

Patient. The patient was a 16-year-old Japanese adolescent (weight $77 \mathrm{~kg}$, height $169 \mathrm{~cm}$ ) who showed unconjugated hyperbilirubinemia soon after birth. He was diagnosed as having type I Crigler-Najjar syndrome on the basis of a complete absence of hepatic bilirubin UDP glucuronyltransferase (EC 2.4.1.17) activity, found at the age of $51 \mathrm{~d}$. The administration of phenobarbital and cholestyramine did not decrease his serum bilirubin concentrations; only phototherapy was effective and prevented kernicterus. Since a majority of the patients with this disease eventually show central nervous system damage by hyperbilirubinemia, the patient had been treated with phototherapy every night for more than $10 \mathrm{~h}$. However, his serum bilirubin concentrations continued to increase year after year. When the serum bilirubin exceeded the bilirubin binding capacity of $14.7 \mu \mathrm{mol}$ bilirubin $/ \mathrm{g}$ serum albumin (i.e., $720 \mu \mathrm{mol} / \mathrm{L}$ bilirubin), an abrupt deterioration of the patient's neurologic status occurred as manifested by difficulty in walking and speaking. At this point, plasmapheresis was conducted.

Methods. Plasmapheresis was carried out twice a week for a total of five mo. The following studies were performed when plasmapheresis treatment had been completed for four mo. After that, the patient received a liver transplant in Australia. In accordance with the Helsinki Declaration, informed consent was 
strictly observed and the study design was approved by the Protection of Human Subjects Committee of Toho University.

In the plasmapheresis, a bilirubin adsorbent column (2) (Plasorba BR-350, Asahi Medical, Tokyo, Japan) was used to remove bilirubin from the plasma (Fig. 1). Blood was drawn from the radial artery at a flow rate of $160 \mathrm{~mL} / \mathrm{min}$ and pumped into a membrane plasma separator (Plasmacure PS-06, Kuraray, Okayama, Japan). The yield of this separation was $40 \mathrm{~mL} / \mathrm{min}$. The plasma was then perfused through the bilirubin adsorbent column and returned to the venous blood line of the plasma separator. The bilirubin adsorbent material consisted of a strong-base, anion-exchange resin (styrene-divinyl benzene) in chloride form on a cellulose acetate filter with a $0.45 \mu \mathrm{m}$ pore size. During the perfusion, sodium heparin was added to the blood in the separator at a rate of $1,000 \mathrm{U} / \mathrm{h}$. The total volume of plasmapheresis was $7 \mathrm{~L}$. An aliquot of plasma was collected every liter of plasmapheresis at the inlet and outlet of the adsorbent system (Fig. 1, sites Pads and Pv). The concentrations of unconjugated bilirubin, retinol and other micronutrients were determined for four perfusions performed on four successive days. Plasma concentrations of retinol, retinyl palmitate, $\alpha$-tocopherol, and $\alpha$ and $\beta$ carotenes were determined by a silver-ion-free HPLC method as described earlier (4). Various plasma constituents in arterial blood specimens collected at the inlet of the plasma separator (Fig. 1, site Pa) before and after 7-L plasmapheresis performed on another five successive days were measured with a Hitachi 7250 analyzer (Hitachi, Tokyo, Japan) using commercial test reagents (Dia-Iatron, Tokyo, Japan). Globulins were obtained by subtracting albumin concentrations from total protein concentrations. Plasma retinol-binding protein (RBP) was measured by the immunonephelometric method (5). Low-density lipoprotein (LDL) was measured by the heparin $/ \mathrm{Ca}^{2+}$ turbidimetric method (6). Differences between paired results were statistically examined by paired $t$-test.

\section{Results and discussion}

Preliminarily, we measured the plasma retinol and albumin-free bilirubin concentrations to confirm that these neurologic symptoms were not due to hypervitaminosis A toxicity but rather to high bilirubin, since retinoic acid (a metabolite of retinol) cannot be excreted in bile as a glucuronide conjugate in type I Crigler-Najjar syndrome (7). His plasma concentration of retinyl palmitate was $39 \mathrm{nmol} / \mathrm{L}$ (reference range: $0-191 \mathrm{nmol} / \mathrm{L}$ ) at the plasma retinol concentration of $2,127 \mathrm{nmol} / \mathrm{L}$ (reference range: $1,050-2,800 \mathrm{nmol} / \mathrm{L}$ ), but the albumin-free bilirubin concentration as determined with the peroxidase oxidation method (8) was $24 \mathrm{nmol} / \mathrm{L}$ (reference range: $\sim 17 \mathrm{nmol} / \mathrm{L}$ ), indicating a likely progression of bilirubin encephalopathy. Hypervitaminosis A (vitamin A toxicity) is associated with increased plasma concentrations of retinyl esters (particularly, of retinyl palmitate) (9).

First, arterial blood specimens were collected at the inlet of the plasma separator before and after 7-L plasmapheresis on five successive days (Fig. 1, site Pa). The 


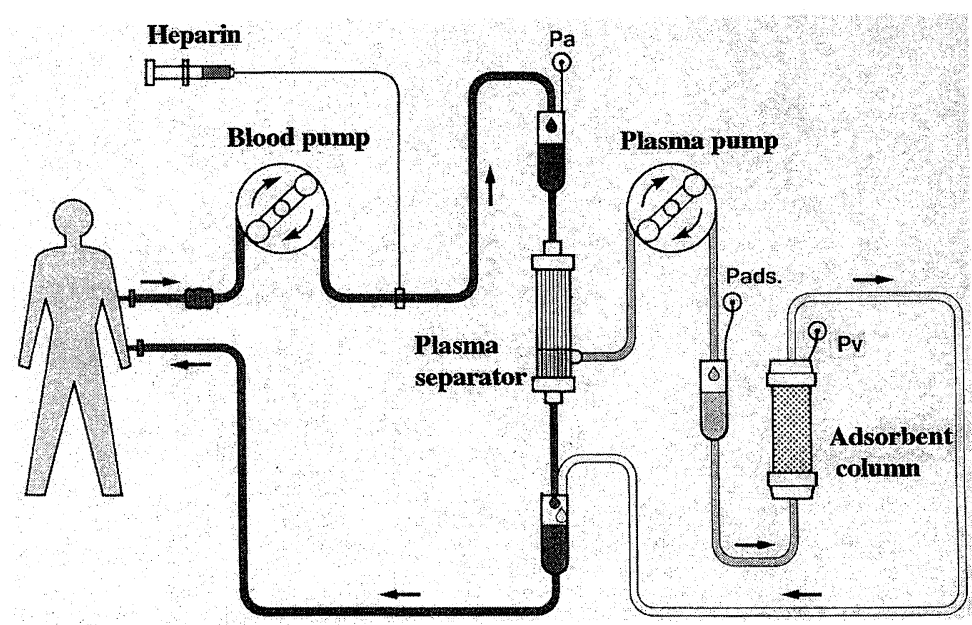

Fig. 1. System of bilirubin adsorption. Plasma samples were collected at the inlet and outlet of the bilirubin adsorbent column (Plasorba BR-350, Asahi Medical; sites Pads and $\mathrm{Pv}$, respectively). Blood specimens were collected at the inlet of the plasma separator (Plasmacure PS-06, Kuraray; site Pa) before and after $7 \mathrm{~L}$ of plasmapheresis.

Table 1. Analysis of plasma constituents ${ }^{\mathrm{a}}$ before and after plasmapheresis treatment in a patient with type I Crigler-Najjar syndrome.

Perfusion

Before

$67 \pm 1$
$48 \pm 1$
$19 \pm 1$
$64 \pm 3$
$143 \pm 12$
$291 \pm 36$
$47 \pm 19$
$441 \pm 104$
, $686 \pm 217$

After (difference)

\section{Protein}

Total (g/L)

Albumin (g/L)

Globulins $(\mathrm{g} / \mathrm{L})$

Uric acid (mg/L)

Cholinesterase (IU/L)

Bilirubin $(\mu \mathrm{mol} / \mathrm{L})$

Retinyl palmitate $(\mathrm{nmol} / \mathrm{L})^{\mathrm{f}}$

Retinol (nmol/L)

RBP (nmol/L)

Before After (difference)

a Arterial blood specimens were collected at the inlet of the plasma separator before and after plasmapheresis on five successive days. Values are means and SD of five perfusions.

${ }^{\mathrm{b}}$ Statistically different from the before-perfusion values at $p<0.01$ (paired $t$-test).

${ }^{\mathrm{c}}$ Statistically different from the before-perfusion values at $p<0.05$ (paired $t$-test).

${ }^{\mathrm{d}}$ Statistically different from the before-perfusion values at $p<0.001$ (paired $t$-test).

e Reference value: 185-431 IU/L.

${ }^{\mathrm{f}}$ Reference value: $0-191 \mathrm{nmol} / \mathrm{L}$. 
data in Table 1 show that the concentration of unconjugated bilirubin in plasma was significantly reduced by the perfusion $(p<0.001)$. We did not measure the change in conjugated bilirubin because its concentration in the plasma of our patient was essentially zero. The plasma concentrations of sodium, potassium, chloride, calcium, inorganic phosphorous, magnesium, iron, urea nitrogen, creatinine, amylase, creatine kinase, aspartate aminotransferase, alanine aminotransferase, lactate dehydrogenase, alkaline phosphatase, gamma-glutamyltransferase, glucose, triglycerides and total cholesterol did not change by the treatment using anion-exchange resin (data not shown), and our findings agree with those in previous reports $(2,3)$. Incompatible with the previous reports, plasma concentrations of total protein, albumin, uric acid and plasma cholinesterase activity were significantly reduced by the perfusion, and this needs further investigation. However, it is important to note that concentrations of RBP were also deleted by the perfusion. The decreased amounts of retinol $(912 \pm 123 \mathrm{nmol} / \mathrm{L})$ were almost equal to those of RBP $(1,010 \pm 192 \mathrm{nmol} / \mathrm{L})$. Geiger et al (2) reported the significant loss of other plasma constituents such as complements $\left(\mathrm{C}_{3}\right.$ and $\mathrm{C}_{4}$ ), immunoglobulins (Ig $\mathrm{A}$, Ig $G$ and Ig M), transferrin, $\alpha_{1}$-antitrypsin, $\alpha_{1}$-glycoprotein, $\alpha_{2}$-macroglobulin, haptoglobin and ceruloplasmin. Despite this, we observed a significant loss of globulins (i.e., sum of the above proteins), and post-perfusion values were within normal range (Table 1).

Next, we closely investigated the concentration of retinol in each liter of plasma taken at the inlet and outlet of the bilirubin adsorbent column (Fig. 1, sites Pads and Pv). Table 2 also displays that the concentration of retinol was significantly decreased to about $50 \%$ of the value before perfusion by perfusion through the

Table 2. Effect of plasma perfusion ${ }^{a}$ using an anion-exchange resin on the concentrations of bilirubin and retinol in a patient with type I Crigler-Najjar syndrome.

\begin{tabular}{|c|c|c|c|c|c|}
\hline & \multicolumn{2}{|c|}{ Bilirubin $(\mu \mathrm{mol} / \mathrm{L})$} & \multicolumn{3}{|c|}{ Retinol $(\mathrm{nmol} / \mathrm{L})$} \\
\hline Before perfusion & \multicolumn{2}{|c|}{$308 \pm 32^{b}$} & \multicolumn{3}{|c|}{$1,492 \pm 138^{\mathrm{b}}$} \\
\hline Perfusion (mL) & at inlet & at outlet & at inlet & at 0 & utlet \\
\hline 1,000 & $214 \pm 36$ & $90 \pm 19(42 \pm 2)^{\mathrm{c}}$ & $952 \pm 162$ & $484 \pm 82$ & $(51 \pm 4)^{\mathrm{c}}$ \\
\hline 2,000 & $200 \pm 37$ & $106 \pm 23(53 \pm 5)$ & $882 \pm 207$ & $597 \pm 20$ & $(66 \pm 10)$ \\
\hline 3,000 & $183 \pm 21$ & $115 \pm 19(63 \pm 4)$ & $758 \pm 133$ & $565 \pm 14$ & $(74 \pm 11)$ \\
\hline 4,000 & $181 \pm 20$ & $118 \pm 15(65 \pm 2)$ & $764 \pm 163$ & $545 \pm 81$ & $(72 \pm 7)$ \\
\hline 5,000 & $171 \pm 22$ & $123 \pm 13(72 \pm 2)$ & $647 \pm 205$ & $469 \pm 16$ & $(72 \pm 8)$ \\
\hline 6,000 & $168 \pm 24$ & $122 \pm 16(73 \pm 2)$ & $640 \pm 62$ & $501 \pm 8$ & $(79 \pm 8)$ \\
\hline 7,000 & $169 \pm 19$ & $126 \pm 14(75 \pm 2)$ & $652 \pm 95$ & $520 \pm 74$ & $(80 \pm 8)$ \\
\hline After perfusion & \multicolumn{2}{|c|}{$173 \pm 16^{\mathrm{b}}$} & \multicolumn{3}{|c|}{$737 \pm 55^{\mathrm{b}}$} \\
\hline
\end{tabular}

${ }^{\text {a }}$ Values are means and SD of four perfusions performed on four successive days.

${ }^{\mathrm{b}}$ Values in blood collected at the inlet of a membrane plasma separator.

${ }^{\mathrm{c}}$ Rates of removal (\%) were calculated as (concentration after perfusion at outlet of the resin column)/(concentration before perfusion at inlet of the resin column). 
anion-exchange resin. In the first liter of perfusate, $58 \%$ of the bilirubin was adsorbed while only $49 \%$ of the retinol was removed $(p<0.01)$; however, no significant differences in the removal of these analytes were found at 3 and $7 \mathrm{~L}$ of perfusion. On the four successive days when perfusion was performed, the concentration of retinol before perfusion was 1,668 on day $1,1,338$ on day $2,1,446$ on day 3 and $1,516 \mathrm{nmol} / \mathrm{L}$ on day 4 . The mean $( \pm \mathrm{SD})$ retinol was $1,492 \pm 138 \mathrm{nmol} / \mathrm{L}$; these decreased to $784,770,731$ and $662 \mathrm{nmol} / \mathrm{L}$ following perfusion on the four successive days (mean $\pm \mathrm{SD}, 737 \pm 55 \mathrm{nmol} / \mathrm{L}$ ). Although plasma retinol after perfusion was decreased to vitamin A deficiency levels $[<1,050 \mathrm{nmol} / \mathrm{L}(7)]$, it returned to normal on the next day; presumably stored retinol in the liver was secreted into the circulation. Since humans have a large capacity for storing retinol in the liver (10) and the turnover of RBP is extremely fast $(11,12)$, symptoms associated with hypovitaminosis A were not manifested in our patient. We work out ca. $4,000 \mathrm{~mL}$ of circulating plasma volume in the patient from his body weight $(77 \mathrm{~kg})$ and venous hematocrit value $(37 \%)$. Thus, maximally $3,600 \mathrm{nmol}$ of retinol will be lost per $\mathrm{d}$, since $500-900 \mathrm{nmol} / \mathrm{L}$ of retinol was deleted by $7 \mathrm{~L}$ of plasmapheresis. As studies on daily food intake revealed that the patient took more than $3,000 \mathrm{IU}$ $(\approx 3,490 \mathrm{nmol})$ of retinol from the diet per $\mathrm{d}$ at that time, the losses by plasmapheresis were as much as the daily oral intake of retinol. Accordingly, daily requirement should be provided with hepatic vitamin A stores. Here, the requirements $(1,971 \mathrm{nmol})$ were based on the order of $22 \mathrm{IU}(25.6 \mathrm{nmol})$ per kilogram per body weight per d (13). We also calculated how many times it takes for perfusion to exhaust liver storage. The average adult will have $250 \mathrm{nmol}$ of retinol in each gram of liver (13). The patient's hepatic vitamin A stores would be estimated at $442,750 \mathrm{nmol}$ from his liver weight of $1,771 \mathrm{~g}(2.3 \%$ of the body weight). Our patient may have a 224-d supply of retinol in the liver, if the plasmapheresis treatment is performed every day. We should measure plasma retinol concentrations during plasmapheresis treatment coupled with an anion-exchange resin column to estimate the loss of retinol.

In the absence of the anion-exchange resin, bilirubin (2) and retinol were not removed by the membrane plasma separator, most likely because unconjugated bilirubin is tightly bound to albumin (3), and retinol is bound to both RBP and prealbumin (7). The addition of anion-exchange resin to the system makes the removal of bilirubin from plasma possible. The removal mechanism is likely anion exchange: the resin binds the carboxylic acid groups of bilirubin (COO), and releases $\mathrm{Cl}$ ions from the resin (14). Although retinol does not have carboxylic acid groups, it binds to the resin (presumably as a form of holo-RBP) owing to the strong hydrophobic character of both resin and retinol. We found that $\mathrm{Cl}$ concentrations were unaffected and remained stable throughout the perfusion. Furthermore, the concentrations of retinyl palmitate (an ester of retinol), $\alpha$-tocopherol and carotenes did not change significantly. In a future study, we plan to test whether other anion-exchange resins (15) (e.g., weak-base resins) are also capable of adsorbing retinol along with bilirubin during plasmapheresis for hyperbilirubinemia. We 
Table 3. Plasma retinol and RBP levels ${ }^{a}$ before and after LDL apheresis for three familial hypercholesterolemic patients.

\begin{tabular}{lcc}
\hline & \multicolumn{2}{c}{ LDL apheresis } \\
\cline { 2 - 3 } & Before & After \\
\hline LDL $(\mathrm{mg} / \mathrm{L})^{\mathrm{b}}$ & $10,624 \pm 1,677$ & $2,236 \pm 483^{\mathrm{c}}$ \\
Retinol (nmol/L) & $1,993 \pm 164$ & $1,615 \pm 388^{\mathrm{d}}$ \\
RBP $(\mathrm{nmol} / \mathrm{L})$ & $1,889 \pm 345$ & $1,413 \pm 225^{\mathrm{d}}$ \\
Retinol/RBP ratios & $1.11 \pm 0.18$ & $1.14 \pm 0.28$ \\
\hline
\end{tabular}

${ }^{a}$ Values are means and SD of three duplicate analyses.

${ }^{\mathrm{b}}$ Reference value: $1,880-4,920 \mathrm{mg} / \mathrm{L}$.

${ }^{\mathrm{c}}$ Statistically different from the before-perfusion values at $p<0.001$ (paired $t$-test).

${ }^{\mathrm{d}}$ Statistically different from the before-perfusion values at $p<0.05$ (paired $t$-test).

measured plasma retinol levels in three cases of familial hypercholesterolemia treated with LDL apheresis by passage through a dextran sulfate column (a cation-exchange resin column; Kaneka Liposorber LA15 System, Tokyo, Japan) (16). When 4,000 mL of plasma were treated, retinol levels were significantly decreased (Table 3). RBP levels were also reduced, exhibiting similar retinol/RBP ratios before and after LDL apheresis. This suggested that decreases in retinol concentration would also be reflected by RBP levels. Here, RBP would be protonic, since proteins are "zweitterions."

In this investigation, we found that unconjugated bilirubin was removed from plasma of a patient with Crigler-Najjar syndrome by plasmapheresis and passage of the plasma through an anion-exchange resin. Our result is based on only one case; nevertheless, it is important because few patients with type I Crigler-Najjar syndrome live without treatment such as plasmapheresis, since liver transplantation is ethically unusual in Japan. During this therapy, which was performed twice a week for five mo, there was a temporary decrease in the concentration of plasma retinol, which returned to normal the day after plasmapheresis. The decrease was associated with the reduction of plasma retinol-binding protein. The patient may have sufficient supply of retinol in the liver. The return of the plasma retinol level to normal the day after plasmapheresis makes the possibility of vitamin A deficiency highly improbable.

The authors are particularly indebted to Dr. John A. Lott, Professor of Pathology, Ohio State University Medical Center, for his help in the preparation of this paper and the many useful suggestions for its improvement. The authors are also indebted to Mr. Kazuhiro Kunimi and the Clinical Chemistry Laboratory at Mitsubishi Kagaku Bio-Clinical Laboratories, Inc. for assistance with the retinol-binding protein measurement. 


\section{REFERENCES}

1) Miyazaki M, Sakagami K, Shiozake S, Saito S, Matsuoka J, Orita K. 1988-89. Bilirubin removal by anion exchange resin in post-operative liver failure. Biomat Art Cells Art Org 16: 977-983.

2) Geiger H, Klepper J, Lux P, Heidland A. 1992. Biochemical assessment and clinical evaluation of a bilirubin adsorbent column (BR-350) in critically ill patients with intractable jaundice. Int J Artif Organs 15: 35-39.

3) Davies CR, Malchesky PS, Saidel GM. 1990. Temperature and albumin effects on adsorption of bilirubin from standard solution using anion-exchange resin. Artif Organs 14: 14-19.

4) Ihara H, Ishiwata Y, Hashizume N. 1997. Metabolism of retinol oleate in healthy women after vitamin A ingestion. Clin Chem Enzym Comms 7: 365-372.

5) Shima H, Okano H, Tadokoro S, Hirose K, Tomuro Y, Huruki S, Sato N, Ito K, Kubouchi T. 1994. Evaluation of the assays of serum transferrin, retinol binding protein, and prealbumin by Behring Nephelometer Analyzer (BNA) (in Japanese). Jpn J Med Pharm Sci 32: 145-153.

6) Koide A, Kawai T, Kubota N. 1975. Analysis of serum lipoproteins by precipitation with heparin and calcium ions (in Japanese). Rinsho Byori 21 (Special number): 82-91.

7) McCormick DB, Greene HL. 1994. Vitamins. In: Tietz Textbook of Clinical Chemistry, 2nd ed (Burtis CA, Ashwood ER, eds), p 1278-1280. WB Saunders Co, Philadelphia.

8) Nakamura H, Lee Y. 1977. Microdetermination of unbound bilirubin in icteric newborn sera: An enzymatic method employing peroxidase and glucose oxidase. Clin Chim Acta 79: $411-417$.

9) Smith FR, Goodman DeWS. 1976. Vitamin A transport in human vitamin A toxicity. $N$ Engl $J$ Med 294: 805-808.

10) Blaner WS, Olson JA. 1994. Retinol and retinoic acid metabolism. In: The Retinoides; Biology, Chemistry and Medicine, 2nd ed (Sporn MB, Roberts AB, Goodman DeWS, eds), p 229-255. Raven Press, New York.

11) Soprano DR, Blaner WS. 1994. Plasma retinol-binding protein. ibid, p 257-281.

12) Vahlquist A. 1972. Metabolism of the vitamin-A-transporting protein complex: Turnover of retinol-binding protein, prealbumin and vitamin A in a primate (Mecaca irus). Scand J Clin Lab Invest 30: 349-360.

13) McGilvery RW. 1970. Supply of vitamin A. In: Biochemistry: A functional approach (McGilvery RW, ed), p 645-646. WB Saunders Co, Philadelphia.

14) Faenza S, Balestri M, Martinelli G, Spighi M, Fini M, Giardino R, Coli L, Cianciolo G, Stefoni S, Bonomini V. 1992. Hemoperfusion with a new anion exchange resin corrects the metabolic alkalosis in pyloric stenosis: An experimental demonstration. Int $J$ Artif Organs 15: 677-680.

15) Tang DH, Malchesky PS, Omokawa S, Matsushita M, Davies CR, Nose Y. 1989. Temperature effect on bilirubin adsorption with the anion-exchange resin BR-601. Int $J$ Artif Organs 12: 659-663.

16) Lepage S, Bonnefont-Rousselot D, Bruckert E, Bourely B, Jaudon MC, Delattre J, Assogba U. 1996. Antioxidant status of hypercholesterolemic patients treated with LDL apheresis. Cardiovasc Drugs Ther 10: 567-571. 